\title{
An empirical study towards understanding user acceptance of bring your own device (BYOD) in higher education
}

\author{
Gary Cheng \\ Department of Mathematics and Information Technology, The Hong Kong Institute of Education, Hong \\ Kong
}

Yuanyuan Guan \& Juliana Chau

The English Language Centre, The Hong Kong Polytechnic University, Hong Kong

\begin{abstract}
This paper discusses the findings of a research study investigating user acceptance of bring your own device (BYOD) practice to support teaching and learning in a Hong Kong university. Forty-four undergraduate students and two teachers participated in the study. To collect their ratings of agreement with respect to several BYOD-related issues, student participants were asked to complete pre- and post-user acceptance questionnaires at the beginning and at the end of a 13-week semester. Post-event focus group interview sessions were also organised to further elicit students' and teachers' views on the use of personally owned devices for learning. While most of the findings from this study support the use of BYOD in higher education, a number of concerns about its implementation are raised. Insights derived from this research will help inform pedagogies, research and practices in BYOD-mediated learning environments.
\end{abstract}

\section{Introduction}

Rapid advances in technological innovation have transformed traditional classroom practices, redefined the roles of teachers and students, and given rise to various forms of education such as online learning and blended learning. With the ever-increasing presence of mobile technology in our daily life, a substantial body of studies have been undertaken to investigate the impacts of mobile technology on learning. Some studies attempted to address the motivational and affective issues of technology use such as students' attention (Sung, Chang, Lee, \& Yu, 2008), motivation for learning (Rau, Gao, \& Wu, 2008), and engagement with pedagogical activities (Huizenga, Admiraal, Akkerman, \& ten Dam, 2009). Some others were designed to explore how technology could foster cognitive learning through technology-mediated activities like game playing (Schwabe \& Göth, 2005), blogging (Huang, Jeng, \& Huang, 2009), note-taking (Lai, Yang, Chen, Ho, \& Chan, 2007), and adaptive content delivery (Shen, Wang, \& Pan, 2008).

With the prevalence of mobile devices and a growing appetite amongst adolescents for access to digital resources and virtual communities on-the-go, there has been a trend in recent years to encourage students to bring their personally owned devices to the classroom for learning purposes (Norris \& Soloway, 2011). The notion of bring your own device (BYOD) originated from the corporate sector. In 2009, the Intel Company realised that its employees used their own devices such as laptops, smartphones, tablet PCs, to connect to the corporate network, resulting in productivity increase and cost savings. Since then, the BYOD approach has been gaining in popularity in the business world and branching out into other sectors such as education (Harkins, 2013).

In the context of education, BYOD and mobile learning are conceptually similar but each with a different focus in terms of affordance. BYOD focuses primarily on the use of a personally owned mobile device and its associated technology to facilitate personalised learning (Afreen, 2014; Kong \& Song, 2015; Lai, Khaddage, \& Knezek, 2013). Personalised learning refers to the learning processes that give priority to student choice and voice, and that support students to take more responsibility and control over their learning (Looi et al., 2009). On the other hand, mobile learning concerns itself mainly with the range of ubiquitous learning opportunities offered by mobile devices and wireless Internet access (Kukulska-Humle \& Traxler, 2005). Ubiquitous learning has its origin in ubiquitous computing and is defined as "the potential of computer technology to make learning possible at any time and at any place” (Hwang, 2006; p. 72). Under this definition, ubiquitous learning encompasses the learning environments that enable students to access learning content without spatial and temporal limitations, but it does not necessarily require a personally owned mobile device. 
Both the BYOD and mobile learning approaches share a common affordance in that they involve the utilisation of movable devices to access multimedia resources and/or to participate in online communities for educational purposes. In BYOD, however, students can potentially connect to friends and resources anytime and anywhere via their own personal devices rather than the ones borrowed from the school for a limited duration. They may also have a greater sense of ownership over their learning and the technology required for learning (White, 2015). These features can be leveraged to better cultivate a seamless learning environment where personalised learning can take place across multiple spaces and time scales (Toh, So, Seow, Chen, \& Looi, 2013). Given this seamless learning environment, students can pursue individual learning pathways to meet their diverse learning needs (Looi et al., 2009). The perceived value of BYOD for education was confirmed, for example, by a pilot study involving several secondary schools in Alberta several years ago. Their findings noted that a BYOD approach had the effect of dismantling the border between in- and out-of-class activities, thereby opening up new vistas for learning (Alberta Education, 2012). Similar effect can also be found in the higher education context where a BYOD strategy could empower students to take an active role in independent learning (Al-Okaily, 2013; Hamza \& Noordin, 2013) and reflective engagement (Kong \& Song, 2015), both inside and outside the classroom.

Although prior studies have demonstrated the potential of BYOD for education, user acceptance towards implementing the BYOD approach for teaching and learning is still understudied. It is worth investigating the issue of user acceptance because further evidence can inform BYOD-mediated pedagogy and policy in education. To fill the research gap, this study aims to: (1) explore user acceptance towards using a BYOD approach in an English course at university level; and (2) identify the benefits and concerns of a BYOD approach from the perspectives of students and teachers. The results of this study will furnish insights into students' and teachers' perception of the importance and value of a BYOD approach in teaching and learning. Additionally, the findings of this study will help inform pedagogies, research and practices in BYOD-mediated learning environments.

\section{Literature review}

\section{Potentials and challenges of BYOD in education}

The potentials and challenges of BYOD in education have attracted considerable interest in recent years. Key issues germane to BYOD are examined at two different levels: (1) the school level; and (2) the teaching and learning level. At the school level, one notable benefit of the BYOD policy is that schools can follow technological trends in education without having to invest substantially in manpower and equipment (Horizon Project, 2013). New BYOD policy could also create opportunities to promote technology etiquette and ethics in school, leading to the development and enforcement of acceptable use policy of information technology in the long term (Clifford, 2012; Stavert, 2013).

At the teaching and learning level, BYOD can render one-to-one learning affordable and accessible to students whose proficiency in using the devices can help them to become more independent learners. In contrast to the traditional teacher-fronted classroom, BYOD facilitates student-centred learning given students' freedom to determine the what and how of learning using their devices. Teachers can provide differential instruction to students based on their level of understanding and create a more interactive, interesting and engaging learning atmosphere (Alberta Education, 2012; Handal, 2015). More importantly, recent studies have shown that BYOD is conducive to the development of twenty-first century skills such as digital literacy and fluency, critical thinking, problem solving and collaboration (Clifford, 2012; Dündar \& Akçayır, 2014; Hopkins, Sylvester, \& Tate, 2013; Rackley \& Viruru, 2014).

For all the stated merits of BYOD for education, most mobile devices manifest a number of limitations related to the features and technical specifications such as small screen size, short battery life, limited processing power and memory. The limitations could have a detrimental effect on user acceptance of BYOD. BYOD may also give rise to issues of digital disparity between economically affluent and disadvantaged students, and distract students from learning because of the easy access to social media and digital games while in class (Taneja, Fiore, \& Fischer, 2015). On the teacher side, creating a BYODenhanced learning environment and facilitating students to learn with their own devices can pose challenges to well-established instructional practices. Teachers may need to undergo training for the development of BYOD-oriented practices. Taking all the challenges and difficulties into account, successful implementation of BYOD depends on collaboration at every level of the education system, including 
rigorous enforcement of acceptable use policies and thoughtful consideration for pedagogical design (Afreen, 2014; Burns-Sardone, 2014; Dündar \& Akçayır, 2014).

\section{Using BYOD in higher education}

While the educational use of electronic devices provided by institutions is well documented, only a handful of empirical studies have examined the effects of BYOD on student learning. Some of these studies scrutinised students' use of their own devices to enhance engagement and achievement (Al-Okaily, 2013), academic efficiency (Hamza \& Noordin, 2013), and student-teacher interaction (Imazeki, 2014). Others were designed for professional development such as teacher education, where students were trained to be proficient in the use of BYOD for their profession (Burns-Sardone, 2014; Kong \& Song, 2015; Smith \& Byrum, 2013).

The range of mobile applications (apps) at the disposal of researchers and practitioners in implementing the BYOD approach varies. Different mobile apps can support a variety of human activities (Clough, Jones, McAndrew, \& Scanlon, 2008), but the BYOD literature tends to rely on using mobile apps for referential activities (e.g. getting access to digital resources), reflective activities (e.g. reviewing recorded notes), data collection activities (e.g. taking photos and jotting down memos), and constructive activities (e.g. taking notes individually or contributing ideas to online communities). For example, Al-Okaily (2013) implemented a BYOD initiative in the intensive English language programme offered by a university at United Arab Emirates. Students were asked to use their own devices for classwork, homework assignments, communication and course management. To develop their language and critical thinking skills, students were encouraged to use their devices for various activities both inside and outside the classroom. These activities include using dictionary apps to look up meanings of words, searching and organising online information to answer questions, creating short videos to demonstrate presentation skills, blogging and commenting on blogs, communicating and sharing with peers on a social networking platform called Edmodo (http://www.edmodo.com). Al-Okaily (2013) concluded that the BYOD-supported learning activities had a positive impact on student engagement with language learning and on their writing performance.

Imazeki (2014) harnessed the power of communicative technology to enhance teacher-student interaction in class. The class teacher asked questions and students submitted answers to a classroom response system called Poll Everywhere (http://www.polleverywhere.com) on their own devices. Students were able to see their responses instantly on the Web or in a PowerPoint presentation. It was identified that this BYOD approach was different from using the traditional handheld clickers in two ways. Firstly, the former offered flexibility in question types (e.g. open-ended questions) while the latter was often limited to multiple-choice questions or questions with numeric answers. Additionally, given this flexibility, it could enable the teacher to create a backchannel for students to raise questions and comments in and out of class. Imazeki (2014) found that this BYOD approach could motivate students to share their thoughts and enhance their understanding of the learning progress.

In a teacher education programme, Burns-Sardone (2014) asked a group of pre-service teachers to read a children's story, produce a book review and share their individual work with the class. They were first instructed to verbally record their book review and convert the recording to a QR code on their smartphones using a mobile application called Audioboo (http://audioboo.fm). They were also asked to print out the QR code and taped it to the book that they had reviewed. They could then listen to and learn from the recordings of other book reviews by scanning the corresponding QR codes using a mobile application called QR Reader. It was found that this BYOD approach could engage students with learning tasks. This finding is consistent with that of Smith and Byrum's (2013) study of leveraging students' devices to produce and troubleshoot their own videos.

Kong and Song (2015) conducted a project underpinned by the concepts of BYOD and flipped classroom at a higher education institute in Hong Kong. Twenty-six in-service teachers were involved in a professional development programme designed to help them implement effective eLearning at their schools. They were asked to use their own devices to undertake learning activities in and out of class. In class, participants could use their devices to access lecture notes and follow links to external learning resources. They could also search relevant information on the Web to facilitate their discussion and presentation on various eLearning topics. Outside class, participants were instructed to use the Edmodo application to read online 
articles and then participate in peer discussion. They were also required to write reflective notes on their understanding of eLearning and prepare a school-based eLearning plan using the same app. Kong and Song (2015) showed that the hybrid approach of BYOD and flipped classroom could advance professional knowledge and promote reflective inquiry for professional development.

\section{Technology acceptance model}

The technology acceptance model (TAM) was first proposed by Davis (1989) to predict user acceptance of information technology from two perspectives: perceived usefulness (PU) and perceived ease of use (PEOU). PU is defined as "the degree to which a person believes that using a particular system would enhance his or her job performance", whereas PEOU refers to "the degree to which a person believes that using a particular system would be free of effort” (p.319). The two main constructs determine individuals' behavioural intention to use a new technology or system. Venkatesh and Davis (2000) extended the original TAM by including external variables such as individual differences, system characteristics, social influence, and facilitating conditions as the determinants of perceived usefulness and perceived ease of use. This extended version was called TAM2. Following a review of eight prominent technology acceptance models, Venkatesh, Morris, Davis, and Davis (2003) developed and validated a unified model with empirical evidence for technology acceptance, named unified theory of acceptance and use of technology (UTAUT). They undertook a test to examine 32 main effects from the extant models, and identified four direct determinants of behavioural intention or usage, which include performance expectancy, effort expectancy, social influence, and facilitating conditions. By definition, performance expectancy is very similar to perceived usefulness and effort expectancy to perceived ease of use in the TAM model. Social influence is a new construct which is defined as "the degree to which an individual perceives that important others believe he or she would use the new system” (p.451). Facilitating conditions is also a new construct, which refers to "the degree to which an individual believes that an organizational and technical structure exists to support use of the system" (p.453). The UTAUT model also found three other constructs, namely, selfefficacy, anxiety and attitude, that have an indirect impact on behavioural intention.

Research on technology acceptance in the educational context has so far generated inconclusive findings. Shroff, Deneen, and Ng (2011) found that perceived ease of use, rather than perceived usefulness, had a direct and significant impact on students' attitudes towards usage of electronic portfolio (ePortfolio) in a higher institution at Hong Kong. By contrast, Park (2009) indicated that perceived ease of use, perceived usefulness and subjective norm (i.e. the perceived social pressure to conduct a behaviour or not) significantly affected students' attitudes towards e-learning in a Korean university. Hopkins et al. (2013) adopted a hybrid version of the decomposed theory of planned behaviour (D-TPB) model (Taylor \& Todd, 1995) and the TAM model (Davis, 1989) to design a questionnaire that sought information from nine New Zealand secondary schools to assess students' behavioural intention in using BYOD for learning. The questionnaire consisted of three dimensions of attitude (i.e. perceived usefulness, perceived ease of use, and compatibility), subjective norms (i.e. influences from teachers, parents and peers), and perceived behavioural control (i.e. self-efficacy, learning autonomy and facilitating conditions). The results of the questionnaire showed that students' behavioural intention to use their own devices was influenced substantially by their attitude and moderately by their subjective norms and perceived behavioural control. Given the limited research on user acceptance of BYOD in Asian universities, this paper aims to bridge this gap by evaluating user acceptance of using BYOD to support English language learning in a Hong Kong university using the TAM model.

\section{Study context}

Staff and students at the Hong Kong Polytechnic University (PolyU) are provided with free Wi-Fi access on campus. They can connect their mobile devices to the university network in nearly all campus facilities such as laboratories, libraries, lecture theatres and general purpose classrooms. Wi-Fi service is also available off-campus through collaboration with local wireless service providers. PolyU staff and students can enjoy free Internet access at thousands of hotspots around Hong Kong.

This study was carried out as part of a university-funded project to investigate the use of BYOD at the English Language Centre (ELC) of the Hong Kong Polytechnic University between January and May 2015. The ELC adopts a blended mode of delivery for most of its English courses: face-to-face meetings supplemented by a range of e-learning initiatives to promote independent learning. One example is the web- 
based ePortfolio (http://eportfolio.elc.polyu.edu.hk) designed to help students develop, self-evaluate and reflect on their own English language abilities. Participants of this study were students enrolled on an Advanced English for University Studies (AEUS) course, with three intended learning outcomes: (1) to research relevant academic texts for a topic and integrate the sources into a position argument essay appropriately and effectively; (2) to plan, research for, write and revise a position argument essay; and (3) to present and justify views effectively in an mini oral defence.

For the purpose of the project, BYOD learning activities were developed and embedded into the AEUS course. These activities included the analysis of thesis statements, the structure of body paragraphs, citation skills, and referencing skills, with web-based sources drawn from YouTube videos (http://www.youtube.com) and online learning activities that were supported by technological tools such as Padlet (http://padlet.com), the ePortfolio, and the ELC's e-learning platform (http://elearn.elc.polyu.edu.hk). As an example, a class plan of BYOD learning activities and students' use of their personally owned device in the AEUS class are shown in Table 1 and Figure 1, respectively.

Table 1

A class plan for BYOD learning activities

\begin{tabular}{|c|c|c|}
\hline \multicolumn{2}{|c|}{ Topic: Citation and Referencing } & $\begin{array}{l}\text { Duration: } 60 \\
\text { minutes }\end{array}$ \\
\hline \multicolumn{3}{|c|}{$\begin{array}{l}\text { Learning objective (LO): } \\
\text { By the end of this session students will be able to: } \\
\text { i. Use appropriate citation styles in their position argument essay } \\
\text { ii. Use appropriate citation techniques - quote, paraphrase and summary }\end{array}$} \\
\hline \multicolumn{2}{|c|}{ BYOD learning activity (LA) } & Activity type \\
\hline \multirow[t]{2}{*}{$\begin{array}{l}\text { In- } \\
\text { class } \\
\text { Stage } 1\end{array}$} & $\begin{array}{l}\text { LA1. Read the sample research-driven position argument essay and the } \\
\text { four extracts on Padlet and discuss the following questions in a } \\
\text { small group: } \\
\text { Q1. What is citing and referencing? } \\
\text { Q2. Why are citing and referencing essential in academic } \\
\text { writing? } \\
\text { Q3. When to reference? }\end{array}$ & $\begin{array}{l}\text { Collaborative, } \\
\text { referential and } \\
\text { discussion } \\
\text { activity }\end{array}$ \\
\hline & $\begin{array}{l}\text { LA2. Watch a video and take notes on referencing (Massey University) } \\
\text { https://www.youtube.com/watch?v=SOEmM5gmTJM }(1: 01 \sim 2: 20 \text {, } \\
\text { 3:12 4:18) }\end{array}$ & $\begin{array}{l}\text { Independent, } \\
\text { referential and } \\
\text { constructive } \\
\text { activity }\end{array}$ \\
\hline \multirow[t]{2}{*}{ Stage 2} & $\begin{array}{l}\text { LA3. Read through the sample essay and discuss } \\
\text { Q1. How does the author cite the sources in the text? - Integral / } \\
\text { Non-integral citation } \\
\text { Q2. Why does the author use the sources in those ways? } \\
\text { Q3. How do you know where those sources are from? }\end{array}$ & $\begin{array}{l}\text { Collaborative, } \\
\text { reflective and } \\
\text { discussion } \\
\text { activity }\end{array}$ \\
\hline & $\begin{array}{l}\text { LA4. Work in groups to search the internet to identify resources on the } \\
\text { referencing style and share it in terms of the following categories } \\
\text { on Google Drive. Co-construct a table of different referencing } \\
\text { styles on Padlet. } \\
\text { 1. Group 1: One author (edited) book, book chapter, journal } \\
\text { article, electronic sources, etc.; first/subsequent in-text } \\
\text { citation, end-of-text citation } \\
\text { 2. Group 2: Two authors journal articles (single author, more } \\
\text { than three authors) } \\
\text { 3. Group 3: Three to five authors } \\
\text { 4. Group 4: Six and more authors }\end{array}$ & $\begin{array}{l}\text { Collaborative, } \\
\text { referential, } \\
\text { discussion and } \\
\text { constructive } \\
\text { activity }\end{array}$ \\
\hline
\end{tabular}




\begin{tabular}{|c|c|c|c|}
\hline Stage 3 & LA5. & $\begin{array}{l}\text { Work in groups to find examples and rules of how the author uses } \\
\text { quote, paraphrasing and summary respectively in the selected } \\
\text { article. Share the answers on Padlet. } \\
\text { 1. Quote: rules of short and long direct quotes; rules of } \\
\text { modifying direct quote; long direct quote (word count), line } \\
\text { space, font, indent } \\
\text { 2. Paraphrase: effective strategies to paraphrase } \\
\text { 3. Summarise: effective ways to summarise one or more } \\
\text { paragraphs or articles of similar ideas }\end{array}$ & $\begin{array}{l}\text { Collaborative, } \\
\text { referential, } \\
\text { discussion and } \\
\text { constructive } \\
\text { activity }\end{array}$ \\
\hline \multirow[t]{2}{*}{ Stage 4} & LA6. & $\begin{array}{l}\text { Individually complete the online exercise (writing a reference } \\
\text { item) } \\
\text { http://www.uefap.com/writing/writfram.htm }\end{array}$ & \multirow[t]{2}{*}{$\begin{array}{l}\text { Independent } \\
\text { and reflective } \\
\text { activity }\end{array}$} \\
\hline & LA7. & $\begin{array}{l}\text { Individually complete the online exercise (reporting: paraphrase, } \\
\text { summary and synthesis) } \\
\text { http://www.uefap.com/writing/writfram.htm }\end{array}$ & \\
\hline $\begin{array}{l}\text { Post- } \\
\text { class }\end{array}$ & LA8. & $\begin{array}{l}\text { Work on your device to complete the exercise and share your: } \\
\text { (Writing a reference list) } \\
\text { http://www.uefap.com/writing/writfram.htm }\end{array}$ & $\begin{array}{l}\text { Independent } \\
\text { and reflective } \\
\text { activity }\end{array}$ \\
\hline
\end{tabular}

\section{Methodology}

\section{Participants}

Participants in this study involved 44 first-year Hong Kong Chinese students at the PolyU enrolled on the AEUS course. They voluntarily accepted the invitation to take part in this study during the second semester of 2014/15. They came from five academic disciplines: applied biology and chemical technology, civil and environmental engineering, hotel and tourism management, health technology and informatics, and industrial system engineering. Their ages ranged from 18 to 21 years. Two teachers participated in this project and were later interviewed for their views on the use of BYOD to support independent learning. Prior to the study, an ethical review application was approved by the university and an informed consent form was signed by each participant.

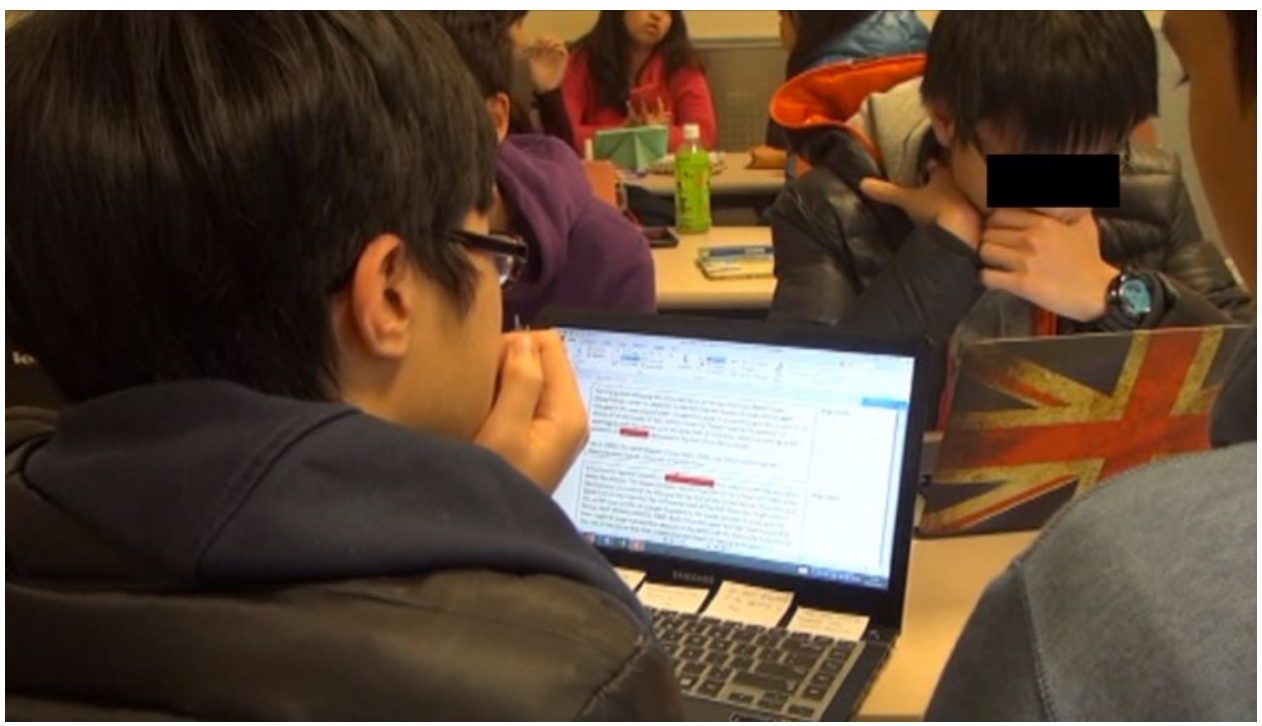

Figure 1. Example of a student's use of a personally owned device in the AEUS class

\section{Data collection and analysis}

Primary data of the pilot were mainly derived from two sources, user acceptance questionnaire for BYOD and focus group interviews. The questionnaire was used to collect student ratings of agreement on several 
learning issues associated with BYOD, while the interviews were designed to further elicit students' and teachers' views on the use of personally owned devices for learning.

User acceptance questionnaire for BYOD

As discussed in the literature review, Shroff et al. (2011) proposed an integrated framework of tertiary students' ePortfolio acceptance based on constructs such as perceived usefulness, perceived ease of use, attitude towards usage, and behavioural intention to use. Hopkins et al. (2013) suggested that secondary students' behavioural intention to use their own devices is significantly influenced by their attitude in terms of perceived usefulness and perceived ease of use. Given their high relevance to the context of the present study, the four constructs employed by Shroff et al. (2011) provided the basis for the BYOD user acceptance questionnaire. The questionnaire in Table 2 consists of 14 items that can be divided into four parts: four items on perceived usefulness (PU), four items on perceived ease of use (PEU), three items on attitudes towards BYOD (ATB), and three items on behavioural intention to use BYOD (BIUB). Student responses are registered on a 5-point Likert scale (where 1 = strongly disagree and $5=$ strongly agree).

Table 2

User acceptance questionnaire for BYOD

\begin{tabular}{ll}
\hline Code & Item \\
\hline PU1. & BYOD helps me learn more effectively. \\
PU2. & BYOD enables me to complete my assignments more quickly. \\
PU3. & BYOD improves my course performance. \\
PU4. & I find BYOD useful to my learning. \\
\hline PEU1. & Using my own device for learning is easy and straightforward. \\
PEU2. & I find my own device easy to use. \\
PEU3. & The BYOD learning resources and platforms are easy to access and use. \\
PEU4. & It is easy for me to become skilful at using my own device for learning. \\
\hline ATB1. & Using my own device for both in-class and out-of-class activities is helpful for learning. \\
ATB2. & Being able to use my own device for learning stimulates my interest in this course. \\
ATB3. & I enjoy using my own device for learning. \\
\hline BIUB1. & I intend to use my own device for learning during the semester. \\
BIUB2. & I intend to use my own device for learning as often an pos............................................. \\
BIUB3. & I will use my own device for learning in future. \\
\hline
\end{tabular}

This study administered a pre- and a post-questionnaire at two points: the beginning and the end of the semester. The 14 items shown in Table 2 constitute the main body of the questionnaires, with changes in verb tenses in the post-questionnaire. In addition to the main body, both questionnaires include a section for general personal particulars like name and age. The post- questionnaire has an extra section on the details of using a personally own device for learning, such as the types of the devices used, the places of use, the activities and duration of use.

The online pre- and post-questionnaires were sent to all student participants via email. Respectively, 40 and 44 responses were returned for the pre- and post-questionnaires, but only 39 participants completed both questionnaires. As as result, 39 samples could be used for a paired $t$-test to evaluate differences in user acceptance of BYOD before and after the study.

Focus group interview

Qualitative data were mainly obtained from six post-event focus group interview sessions at the end of the semester with a total of 9 students and 2 teachers chosen by convenience sampling. Each interview session lasted for approximately 30 to 45 minutes. It was audio-recorded, transcribed verbatim, summarised and thematically categorised using thematic analysis (Braun \& Clarke, 2006). Emerging themes were identified from the transcripts of the interview sessions to cross-validate the quantitative results obtained from the user acceptance questionnaire for BYOD. For students, the interview protocol comprised four guiding questions:

1. Can you describe the course where you used your own device? How is it different from the courses where you were not allowed to use your own device?

2. How did you use your own device to learn in the course? 
3. What changes (in terms of learning attitude, efficiency, interaction and etc.) do you see in yourself brought about by using your own device to learn?

4. What changes do you see in your classmates' behaviour brought about by using their own devices to learn?

The interview questions for teachers were slightly different to those for students. They included:

1. Can you describe the course where you adopted the BYOD approach? How is it different from the courses where students were not allowed to use their own devices?

2. How did you use the BYOD approach for teaching?

3. What changes (in terms of learning attitude, efficiency, interaction and etc.) do you see in your students brought about by using their own devices to learn?

\section{Results}

\section{Results about BYOD usage}

This section presents the types of the devices used (see Table 3), the places of use (see Table 4), and the activities and duration of using personal devices for learning (see Figure 2) collected from the postquestionnaire. Table 3, shows that laptops, smartphones and tablets were the top three most frequently used device types due to their light weight and portability. It is also noted that the majority of respondents owned and used at least two types of devices because the total count of devices used far exceeds the number of respondents.

Table 3

Types of devices used by participants $(N=44)$

\begin{tabular}{lll}
\hline Device type & Count & $\begin{array}{l}\text { Percentage of participants using the device } \\
\text { type }\end{array}$ \\
\hline Laptop & 31 & $70 \%$ \\
Smartphone & 28 & $64 \%$ \\
Tablet & 22 & $50 \%$ \\
Desktop & 14 & $32 \%$ \\
E-book reader & 2 & $5 \%$ \\
\hline
\end{tabular}

With regard to the places of use, Table 4 indicates that all respondents used their devices either at home, at university or while on the move. Fifty-nine percent of respondents reported use of their own devices in all these places. This result slightly differs from those of previous studies (Burns-Sardone, 2014; Imazeki, 2014; Smith \& Byrum, 2013) where most BYOD use cases took place at fixed locations like the home or campus, with relatively few cases about using personal devices on the move reported. One possible reason for the difference is that Hong Kong students tend to spend much time commuting every day and the wireless Internet access is often available on public transport systems. As revealed in the focus group interviews, students sometimes used their devices to read news and access social networking sites on public transport.

Table 4

Places of use by participants $(N=44)$

\begin{tabular}{lll}
\hline Place of use & Count & $\begin{array}{l}\text { Percentage of participants using their } \\
\text { devices at the place }\end{array}$ \\
\hline University, home and on the move & 26 & $59 \%$ \\
University and home & 15 & $34 \%$ \\
Home only & 2 & $5 \%$ \\
University only & 1 & $2 \%$ \\
\hline
\end{tabular}

As seen in Figure 2, over 50\% of respondents spent less than an hour per day on the following activities with their own devices: giving peer feedback (73\%), emailing teachers or classmates (70\%), sharing learning resources (68\%), watching course-related videos (66\%), completing online exercises (61\%), reading articles (59\%), and activities not directly related to learning (52\%). In contrast, a substantial 
percentage of respondents spent more than two hours searching the Internet (48\%) and completing their assignments (57\%) with their devices. Given that the data were collected towards the end of the semester when most students were preoccupied with coursework, the high frequency of personal device use to complete course assignments might perhaps be expected.

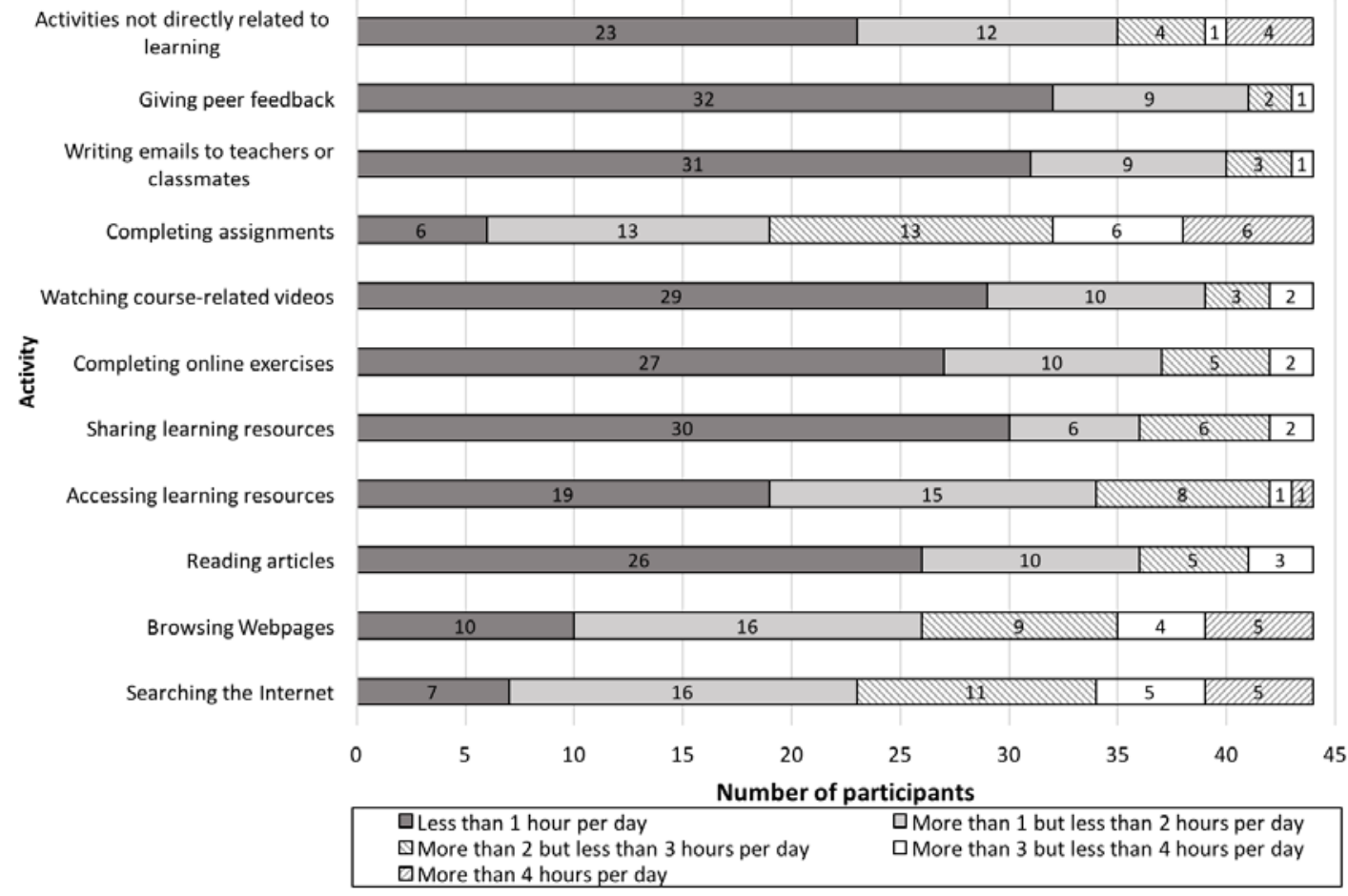

Figure 2. Activities and durations of use by participants $(N=44)$

\section{User acceptance results of BYOD for learning}

Table 5 summarises the reliability statistics for the scales of user acceptance questionnaire. Cronbach's alpha coefficient $(\alpha)$ for each construct of the questionnaire was computed to examine the internal consistency reliability, yielding values ranging from 0.80 to 0.90 for the pre-questionnaire and from 0.82 to 0.94 for the post-questionnaire. The reliability values of all the constructs (i.e. PU, PEU, ATB and BIUB) for both questionnaires were higher than 0.80, suggesting that the items are a valid measure of their underlying construct (Nunnally \& Bernstein, 1994).

Table 5

Reliability statistics for the questionnaire scales

\begin{tabular}{llcc}
\hline Construct & Number of items & \multicolumn{2}{c}{ Cronbach's alpha } \\
& & $\begin{array}{c}\text { Pre } \\
(N=40)\end{array}$ & $\begin{array}{c}\text { Post } \\
(N=\ldots \ldots \ldots \ldots \ldots \ldots \ldots \ldots \ldots . . .\end{array}$ \\
\hline PU & 4 & 0.87 & 0.92 \\
PEU & 4 & 0.80 & 0.89 \\
ATB & 3 & 0.83 & 0.82 \\
BIUB & 3 & 0.90 & 0.94 \\
\hline
\end{tabular}

The descriptive statistics and $t$-test results for the pre- and post-questionnaires are listed in Table 6. Only the samples with both pre- and post-questionnaire results are reported. On average, the items in both questionnaires were given high ratings by respondents $(M=3.38$ to 4.10 and $S D=0.64$ to 1.00$)$, indicating that students held positive attitudes towards BYOD for learning.

Out of the 14 items, PEU2 (4.10), ATB3 (3.95), PEU4 (3.90) and BIBU3 (3.90) were rated highest in the pre- questionnaire while the lowest ratings were noted for PU3 (3.56), ATB1 (3.74), ATB2 (3.74) and 
PEU1 (3.74). In the post-questionnaire, the ratings of PEU2 (4.05), ATB1 (4.00) and PU2 (3.92) were the highest while ATB2 (3.38), PU3 (3.49) and PEU4 (3.69) received the lowest ratings. Results obtained from the analysis of both questionnaires consistently show that respondents agreed more with PEU2 but less with PU3 and ATB2. The results indicate students' preference for using their own devices for learning, while expressing doubt about the effectiveness of BYOD in improving academic performance and stimulating interest in the course. The doubt is understandable because it is intuitive to associate academic performance and interest with the nature of the course content and learner's preference. However, verifying claims about a positive correlation between BYOD use and learning improvement or between BYOD use and motivation to learn is never straightforward.

Table 6

Descriptive statistics and t-test results for the pre- and post-questionnaires

\begin{tabular}{|c|c|c|c|c|c|c|c|c|c|c|}
\hline \multirow[t]{3}{*}{ Item } & \multicolumn{4}{|c|}{ Questionnaire } & \multicolumn{3}{|c|}{$\begin{array}{l}\text { Post-pre paired differences } \\
\qquad(N=39)\end{array}$} & \multirow[t]{3}{*}{$t$} & \multirow[t]{3}{*}{$d f$} & \multirow[t]{3}{*}{$\begin{array}{c}p \\
\text { (2-tailed) }\end{array}$} \\
\hline & \multicolumn{2}{|c|}{$\begin{array}{c}\text { Pre } \\
(N=39)\end{array}$} & \multicolumn{2}{|c|}{$\begin{array}{c}\text { Post } \\
(N=39)\end{array}$} & \multirow[t]{2}{*}{$M$} & \multirow[t]{2}{*}{$S D$} & \multirow[t]{2}{*}{$S E$} & & & \\
\hline & $M$ & $S D$ & $M$ & $S D$ & & & & & & \\
\hline PU1 & 3.79 & 0.80 & 3.74 & 0.75 & -0.05 & 0.72 & 0.12 & -0.44 & 38 & 0.66 \\
\hline PU2 & 3.85 & 0.71 & 3.92 & 0.87 & 0.08 & 0.66 & 0.11 & 0.72 & 38 & 0.47 \\
\hline PU3 & 3.56 & 0.79 & 3.49 & 0.76 & -0.08 & 0.81 & 0.13 & -0.60 & 38 & 0.56 \\
\hline PU4 & 3.87 & 0.66 & 3.79 & 1.00 & -0.08 & 0.90 & 0.14 & -0.53 & 38 & 0.60 \\
\hline PEU1 & 3.74 & 0.88 & 3.85 & 0.90 & 0.10 & 0.72 & 0.12 & 0.89 & 38 & 0.38 \\
\hline PEU2 & 4.10 & 0.82 & 4.05 & 0.92 & -0.05 & 0.83 & 0.13 & -0.39 & 38 & 0.70 \\
\hline PEU3 & 3.85 & 0.67 & 3.77 & 0.93 & -0.8 & 0.93 & 0.15 & -0.52 & 38 & 0.61 \\
\hline PEU4 & 3.90 & 0.72 & 3.69 & 0.73 & -0.21 & 0.77 & 0.12 & -1.67 & 38 & 0.10 \\
\hline ATB1 & 3.74 & 0.72 & 4.00 & 0.80 & 0.26 & 0.85 & 0.14 & 1.89 & 38 & 0.07 \\
\hline ATB2 & 3.74 & 0.64 & 3.38 & 0.99 & -0.36 & 0.96 & 0.15 & -2.34 & 38 & $0.03^{*}$ \\
\hline ATB3 & 3.95 & 0.83 & 3.74 & 0.91 & -0.21 & 1.00 & 0.16 & -1.28 & 38 & 0.21 \\
\hline BIBU1 & 3.87 & 0.80 & 3.82 & 0.94 & -0.05 & 0.76 & 0.12 & -0.42 & 38 & 0.68 \\
\hline BIBU2 & 3.82 & 0.82 & 3.87 & 0.92 & 0.05 & 0.94 & 0.15 & 0.339 & 38 & 0.74 \\
\hline BIBU3 & 3.90 & 0.79 & 3.85 & 0.88 & -0.05 & 0.76 & 0.12 & -0.422 & 38 & 0.68 \\
\hline
\end{tabular}

The results of the paired $t$-test in Table 6 reveal no significant differences in the ratings of most items (except ATB2) between pre- and post-questionnaires $(p>0.05)$. In the pre-questionnaire, a clear majority of respondents (75\%) either agreed or strongly agreed that being able to use their own devices for learning stimulated their interest in the course (ATB2). In the post-questionnaire, however, the percentage of agreement on ATB2 significantly dropped from $75 \%$ to $46 \%$ with an obvious decrease in the mean rating of ATB2 from 3.73 to 3.36. Such a change in student views warrants further investigation, as discussed in the ensuing section.

\section{Discussion}

\section{User acceptance and benefits of the BYOD approach}

Quantitative results from this study accords with prior research that most students favour using their own devices for learning (Hopkins et al., 2013), indicating no significant differences in their attitudes towards the use of personal devices for learning before and after the implementation of BYOD. To further elicit students' and teachers' views on the use of personally owned devices for learning, nine students (S1 to S9) and two teachers (T1 and T2) were invited to take part in focus group interview sessions as described in the data collection and analysis section.

\section{Teachers' perspective}

From teachers' perspective, credit was accorded to the variety of in- and out-of class learning activities facilitated by the BYOD approach. Teacher interviewees (T1 and T2) identified using referencing tools, attempting online exercises, looking up words in electronic dictionaries and in the Academic Phrasebank 
(http://phrasebank.manchester.ac.uk/), watching course-related YouTube videos, and sharing and discussing views in online discussion forums and chatrooms, as activities productive of learning.

Additionally, a teacher interviewee (T1) believed that BYOD-supported activities might have accounted for elevated student engagement in learning processes and their ownership of learning. She reported that a class activity was designed to post her questions and gather students' opinions on Padlet, a free online bulletin board for displaying information and sharing ideas. In this activity, students were first asked to use their personal devices to search, collect, filter, analyse and organise useful information on the Web, which was followed by presenting their answers on Padlet. The teacher interviewee (T1) said:

This pedagogical approach could provide students with more opportunities both in class and beyond to work on their own or in groups, so they could develop more independence in their learning and take more ownership of their learning.

Another teacher interviewee (T2) added that the BYOD approach could also enable students to use their own technology and tools to facilitate their learning. He observed that when students were given a choice of bringing their personal devices for learning in class, they tended to use their own technology and adapt it to meet their learning needs. He also found that the BYOD approach could reduce the technological barrier to engaging students in learning activities across class time and personal time. An example was given by him:

Students were asked to work in groups to research a topic and prepare a presentation for the class. They used a variety of tools on their devices to facilitate collaboration in and out of class. Some students used Dropbox to share reading materials, while some others used WhatsApp to discuss issues with group mates and Google Docs to co-edit the presentation files. All these tools were not introduced in class.

Despite the fact that both teacher interviewees saw the potential of BYOD in promoting student engagement and technology-supported learning, they did not think that BYOD itself would be the key factor contributing to students' academic performance. As a teacher interviewee (T2) shared:

I don't think BYOD alone can make a difference. The key point is how you design your lesson to facilitate students to develop independent learning and higher order thinking skills with their own devices. These skills are critical to academic advancement.

Students' perspective

All student interviewees (S1 to S9) agreed that they would prefer to learn with their own devices to the university-provisioned devices on grounds of familiarity and technological proficiency. They reported that it was convenient to access and manage their own learning resources via personally owned devices. As a student interviewee (S1) shared:

I prefer to use my MacBook because I use it every day. If the university provides me with a notebook computer running Windows, I may not know how to use it .... And my device stores my working files from the previous lessons, so it is easy to manage my files and continue my work on my device.

Furthermore, all student interviewees (S1 to S9) appreciated the usefulness and ease of use of BYOD in learning, which can be ascribed to the efficiency that BYOD brings to assignment completion. In particular, BYOD can save time when searching information and accessing learning resources. As a student interviewee (S2) observed:

[O]ne of the focuses of this course is to find a credible source, nowadays many of us find the references from the internet ... It is very difficult for us not to use our own device to search for such information. Very few of us would go to the library and find books. We often use internet resources.

Another student interviewee (S4) expressed a similar view, arguing that the BYOD approach is good for independent learning: 
I think it does help ... if you're using your own device to search resources online, you can find the scholar's essays, find references, and can also help you to practice because there are many online exercises, e.g., writing introduction or conclusion.

One of the most often-cited activities by student interviewees involved responding to teacher questions on Padlet. Some student interviewees (S1, S2, S3, S5, S7) found that posting their messages on Padlet and instantly sharing ideas and multi-modal resources with classmates motivated learning. This finding corroborates results of previous research (Imazek, 2014) that being able to see others' responses can produce a sense of competition and boost student participation. This is echoed by a student interviewee (S7):

Actually it's fun, becoz (sic) ... if we see other groups write something, then we'll think that we have to find something too'. It stimulates us to become more active even though it's online. I am more active becoz (sic) I don't want to lose. Then we will cooperate in a group and find something together ... then we will post it.

In addition to increasing student participation, a student interviewee (S2) found that the activity could also encourage learning from peers. He said:

In class Padlet did help me generate more ideas. Sometimes I noticed that other's views or perspectives are more important than mine, so I would learn from them to have a broader view of analysis.

Apart from in-class interaction, most student interviewees (S3 to S9) commented that BYOD could also promote learning interaction with peers after class. They reported that in preparation for the oral defence (a graded assessment in the AEUS course), they used their smartphones to search learning resources (e.g. academic essays and video clips) on the Internet, to exchange ideas with group mates via instant messaging applications like WhatsApp (http://www.whatsapp.com), and to share the resources among the group via the Google Drive application (http://drive.google.com). They saw BYOD as a novel and interesting platform for peer learning beyond the classroom.

Despite the fun and the competition element reported by participants in the use of personal devices, the questionnaire results indicate a significant decrease in the ratings of BYOD's effect on stimulating interest in the course (ATB2). Seven student interviewees (S3 to S9) argued that their interest in a course does not depend solely on the use of personal devices in class. Rather, the course content and personal preference assume a more important role in arousing and sustaining interest in the course. A student interviewee (S7) explained:

[B]ecoz (sic) ... let's say I love to use my personal device and I hate mathematics. Even though I am allowed to use my device in class, I would not concentrate on my study in mathematics. I am simply not interested in this subject.

In contrast, a few interviewees (S1 and S2) reported that the use of personal devices could enable them to access multimedia resources, and thus stimulated their learning interest. A student interviewee (S2) shared this view:

Paper work does not contain photos or videos. It cannot satisfy my preference. Our generation enjoy using computers and electronic things to do everything. If we are allowed to learn with our own devices, my learning interest would be stimulated. The electronic materials on my personal device are more attractive.

In the above qualitative analysis, the notable benefits of BYOD perceived by students are convenience and usefulness in accessing learning resources and interacting with peers both in and out of the class. However, it is unclear whether the students could identify a positive effect of BYOD on their academic performance. In the questionnaire, item PU3 was specifically designed to seek students' opinion on the effectiveness of BYOD in improving course performance. The ratings on PU3 were relatively low when compared with those of other items (see Table 6), suggesting that some students either disagreed or took a neutral view on 
this item. Six student interviewees (S1, S2, S4, S7 to S9) commented that they did not see a major difference in their course performance attributable to BYOD. They emphasised that learning is a long-term process and can be influenced by multiple factors. One student interviewee (S9), for example, agreed that the use of personal devices for learning is convenient and to some extent may be potentially beneficial to learning, but he believed that BYOD is not the only factor responsible for enhanced performance. His quotation shown below illustrates this point:

No big difference. Using device in class may be convenient for English learning, but not for learning English effectively in a short time ... If we continue to learn in this way, the device could be a tool for us to improve our learning in the future, but it may not be the whole thing.

\section{Concerns about the BYOD approach}

Although the benefits of the BYOD approach for learning are generally recognised, several concerns about its implementation emerge from the findings of the study. The first concern pertains to insufficient battery power and slow wireless Internet access that could interrupt online learning activities in class. Students would not be able to complete the required online tasks or within the agreed time frame, thus impeding the flow of the lesson. To address this concern, two student interviewees (S1 and S8) suggested measures: (1) providing additional power plugs in the classroom for students to re-charge their digital devices; and (2) increasing the signal strength and bandwidth of the wireless link.

As noted by both teacher interviewees (T1 and T2), the second concern about the BYOD approach lies in the possible distraction caused by digital devices. The distraction is likely to worsen, particularly with personally owned devices installed with a range of entertainment or social networking applications. Students can easily be diverted from learning by instant messages, pop-up alerts or even digital games. Some student interviewees (S2, S4, S9) admitted that they and some others were surfing the Internet for fun while the teacher was covering the course content.

On the other hand, some others (S1, S3, S5 to S8) argued that university students should be trusted to monitor their own behaviour in class, whether or not BYOD pedagogies are adopted. They thought that it is a matter of self-discipline rather than a problem caused by a digital device. The following quotation (S3) supports this view:

Distraction from study may be a problem for us, but I think that it is a matter of self-control and self-discipline. As a university student, we can pay attention to the lesson and resist the temptation of our devices. It's fine for me to bring my own device to the class.

Another concern relates to the limited structural options available on personal digital devices. Two student interviewees (S5 and S6), for instance, complained about the difficulty of highlighting or underlining key points on the course notes in PDF format using their smartphones or tablets. Equally difficult was to handwrite their comments on the digital notes. While acknowledging the efficiency of texting, a student interviewee (S3) remarked the use of digital devices had curtailed opportunities for handwriting practice and speaking in real context. She believed that such a limitation would have an adverse effect on students' all-round development, as shown in the following quotation:

Your personal device can help you check and correct the spelling and some grammatical mistakes, so you may rely on it and may not be careful to type in correct words or sentences. To reduce this problem, handwriting your paper may help.

The fourth concern about the BYOD approach centres on teacher readiness and institutional support for the adoption of BYOD. A teacher interviewee (T2) conceded that his colleagues were satisfied with wellestablished pedagogical practices and were unlikely to consider alternative approaches. He further commented that most teachers do not see the need for further training; nor would they take the initiative to update their knowledge and skills. For teachers to be BYOD-ready, teacher training about the technical aspects of BYOD, the pedagogical practices requisite for BYOD implementation, and possible ways to incorporate BYOD practices in the curriculum, need to be considered. Institutional support, be it in the form of infrastructure or professional development, could hold sway in teachers' willingness to trial and adopt innovative BYOD pedagogies. 


\section{Implications}

The results of this study have two implications for researchers and practitioners of BYOD-mediated learning. First, this study adds evidence to highlight the characteristics of BYOD for teaching and learning. It not only indicates that students generally perceived the usefulness and ease of use of their personally owned devices in the learning process, but it also lends further support to the view that BYOD can increase opportunities for students to develop independence and ownership of their learning (Al-Okaily, 2013; White, 2015). From the teachers' perspective, students can be empowered to take more responsibility and control over their learning through a variety of BYOD-supported learning activities - both in and after class. An example of learning activities designed in this study included accessing online resources, taking and reviewing notes, discussing questions in a small group, sharing results of discussion with other groups and attempting individual exercises. Flexibility to allow students to use their own technology and tools for learning purposes proffers an added advantage of reducing the technological barrier to ubiquitous learning and encouraging student engagement with online learning activities beyond the classroom.

Second, this study also contributes to identify elements critical to the success of BYOD-supported teaching and learning. Meaningful and effective learning would take place through integrating these elements into the design and implementation of BYOD practices. From the students' perspective, it would be beneficial to use their devices for: (i) creating and managing their own resources (e.g. assignments); (ii) searching, filtering and organising online resources relevant to the study (e.g. references); (iii) contributing ideas (e.g. responses to the teacher's questions) to the learning community and gaining new perspectives from peers; and (iv) collaborating with peers in group work to co-construct knowledge (e.g. online preparation for oral defence). It is also found that using personal devices to access multimodal resources (e.g. images, videos and audios) could be an element conducive to BYOD-supported learning, but only for students with a strong preference towards multimedia learning.

\section{Concluding remarks}

This study has examined users' attitudes towards the use of personally owned digital devices for teaching and learning at university. The results demonstrate positive attitudes towards the ease of use and usefulness of BYOD as perceived by the students. Learning becomes a ubiquitous, learner-centred and efficient process due to the connectivity and navigability afforded by personal devices. Teaching is made more differential and flexible because of the interactivity and accessibility of teaching resources. Evidence from the study suggests BYOD engenders extended learning experience through sharing and collaboration during which knowledge co-construction among students occurs. For all the reported benefits, findings from the study show up concerns in two main categories: hardware (battery power, Internet access, limited structural options on the digital device); and humanware (distraction to student learning, teacher readiness, institutional approval). To fully enjoy the educational benefits of BYOD, infrastructural support and teacher professional development are required. Additional empirical evidence from broader contexts will expand existing knowledge of BYOD pedagogies.

Three limitations to the study merit mention. One limitation is that as the project is still in progress, the findings of the current study were drawn from a limited data set obtained over a short period and are highly suggestive. More data are needed to allow for a comprehensive and in-depth understanding of user attitudes and the effect of BYOD on learning. The next phase of the study will involve additional samples to facilitate analysis of the pre- and post-survey differences and the relationship between four constructs of the survey. More importantly, in order to gain insight into the effect of BYOD on course performance, pre- and posttests can be administered to elicit information on students' learning outcomes. Another limitation relates to the data that was collected from only one English course. Courses other than language learning and in other tertiary institutions can be considered to illuminate future research on BYOD implementation. The third, and final, limitation relates to students' choice of learning activity, type of digital device, learning medium, and perceived relevance of digital device use to learning, may bear on their learning outcomes. Further efforts to address the issues and limitations identified in the study will enable more robust conclusions to be drawn. 


\section{Acknowledgments}

This research is partially supported by the eLearning and Blended Learning Development Fund from the Hong Kong Polytechnic University.

\section{References}

Afreen, R. (2014). Bring your own device (BYOD) in higher education: Opportunities and challenges. International Journal of Emerging Trends \& Technology in Computer Science (IJETTCS), 3(1), 233236. Retrieved from http://www.ijettcs.org/Volume3Issue1/IJETTCS-2014-02-25-117.pdf

Alberta Education. (2012). Bring your own device: A guide for schools. Edmonton: Alberta Education. Retrieved from http://cuebc.ca/cue/conference_documents/dell/AlbertaEducationBYODGuide.pdf

Al-Okaily, R. (2013). Mobile learning and BYOD: Implementations in an intensive English program. Learning and Teaching in Higher Education: Gulf Perspectives, 10(2), 1-17. Retrieved from http://the.zu.ac.ae/index.php/lthehome/article/view/141/72

Braun, V., \& Clarke, V. (2006). Using thematic analysis in psychology. Qualitative Research in Psychology, 3(2), 77-101. http://dx.doi.org/10.1191/1478088706qp063oa

Burns-Sardone, N. (2014). Making the case for BYOD instruction in teacher education. Issues in Informing Science and Information Technology, 11, 191-201. Retrieved from http://iisit.org/Vol11/IISITv11p191-201Sardone0505.pdf

Clifford, M. (2012). Bring your own device (BYOD): 10 reasons why it's a good idea. Retrieved from http://www.opencolleges.edu.au/informed/trends/bring-your-own-device-byod-10-reasons-why-its-agood-idea/

Clough, G., Jones, A. C., McAndrew, P., \& Scanlon, E. (2008). Informal learning with PDAs and smartphones. Journal of Computer Assisted Learning, 24(5), 359-371. http://dx.doi.org/10.1111/j.1365-2729.2007.00268.x

Davis, F. D. (1989). Perceived usefulness, perceived ease of use, and user acceptance of information technology. MIS Quarterly, 13(3), 319-340. http://dx.doi.org/10.2307/249008

Dündar, H., \& Akçayır, M. (2014). Implementing tablet PCs in schools: Students' attitudes and opinions. Computers in Human Behaviour, 32, 40-46. http://dx.doi.org/10.1016/j.chb.2013.11.020

Hamza, A., \& Noordin, A. F. (2013). BYOD usage by postgraduate students of International Islamic University Malaysia: An analysis. International Journal of Engineering Science Invention, 2(4), 1420. Retrieved from http://www.ijesi.org/papers/Vol\%202\%284\%29/Version-3/C241420.pdf

Handal, B. (2015). Mobile makes learning free: Building conceptual, professional and school capacity. North Carolina, NC: Information Age Publishing.

Harkins, M. (2013). Mobile: Learn from Intel's CISO on securing employee-owned devices. Information Security Media Group. Retrieved from http://www.govinfosecurity.com/webinars/mobile-learn-fromintels-ciso-on-securing-employee-owned-devices-w-264

Hopkins, N., Sylvester, A., \& Tate, M. (2013). Motivations for BYOD: An investigation of the contents of a 21st century school bag. Paper presented at the 21st European Conference on Information Systems, Utrecht, Netherlands. Retrieved from http://aisel.aisnet.org/ecis2013_cr/183

Horizon Project (2013). NMC Horizon Project: Project short list 2013 (K-12 ed.). Austin, TX: New Media Consortium. Retrieved from http://www.nmc.org/pdf/2013-horizon-k12-shortlist.pdf

Huang, Y.-M., Jeng, Y.-L., \& Huang, T.-C. (2009). An educational mobile blogging system for supporting collaborative learning. Educational Technology \& Society, 12(2), 163-175. Retrieved from http://www.ifets.info/journals/12_2/12.pdf

Huizenga, J., Admiraal, W., Akkerman, S., \& ten Dam, G. (2009). Mobile game-based learning in secondary education: Engagement, motivation and learning in a mobile city game. Journal of Computer Assisted Learning, 25(4), 332-344. http://dx.doi.org/10.1111/j.1365-2729.2009.00316.x

Hwang, G. J. (2006). Criteria and strategies of ubiquitous learning. Proceedings of the IEEE International Conference on Sensor Networks, Ubiquitous, and Trustworthy Computing, Los Alamitos, 72-77. http://dx.doi.org/10.1109/SUTC.2006.49

Imazeki, J. (2014). Bring-your-own-device: Turning cell phones into forces for good. The Journal of Economic Education, 45(3), 240-250. http://dx.doi.org/10.1080/00220485.2014.917898

Kong, S. C., \& Song, Y. (2015). An experience of personalized learning hub initiative embedding BYOD for reflective engagement in higher education. Computers \& Education, 88, 227-240.

http://dx.doi.org/10.1016/j.compedu.2015.06.003 
Kukulska-Hulme, A., \& Traxler, J. (Eds.) (2005). Mobile learning: A handbook for educators and trainers. London, UK: Routledge.

Lai, C.-H., Yang, J.-C., Chen, F.-C., Ho, C.-W., \& Chan, T.-W. (2007). Affordances of mobile technologies for experiential learning: The interplay of technology and pedagogical practices. Journal of Computer Assisted Learning, 23(4), 326-337. http://dx.doi.org/10.1111/j.1365-2729.2007.00237.x

Lai, K.-W., Khaddage, F., \& Knezek, G. (2013). Blending student technology experiences in formal and informal learning. Journal of Computer Assisted Learning, 29(5), 414-425. http://dx.doi.org/10.1111/jcal.12030

Looi, C. K., Wong, L. H., So, H. J., Seow, P., Toh, Y., Chen, W., ... Soloway, E. (2009). Anatomy of a mobilized lesson: Learning my way. Computers \& Education, 53(4), 1120-1132. http://dx.doi.org/10.1016/j.compedu.2009.05.021

Norris, C. A., \& Soloway, E. (2011). Learning and schooling in the age of mobilism. Educational Technology, 51(6), 3-12.

Nunnally, J. C., \& Bernstein, I. H. (1994). Psychometric Theory (3rd ed.). New York, NY: McGraw-Hill.

Park, S. Y. (2009). An analysis of the technology acceptance model in understanding university students' behavioural intention to use e-Learning. Educational Technology \& Society, 12(3), 150-162. Retrieved from http://www.ifets.info/journals/12_3/14.pdf

Rackley, R., \& Viruru, R. (2014). Preparing teachers for the BYOD classroom. In M. Searson \& M. Ochoa (Eds.), Proceedings of Society for Information Technology \& Teacher Education International Conference 2014 (pp. 2608-2613). Chesapeake, VA: Association for the Advancement of Computing in Education.

Rau, P.-L., Gao, Q., \& Wu, L.-M. (2008). Using mobile communication technology in high school education: Motivation, pressure and learning performance. Computers \& Education, 50(1), 1-22. http://dx.doi.org/10.1016/j.compedu.2006.03.008

Schwabe, G., \& Göth, C. (2005). Mobile learning with a mobile game: Design and motivational effect. Journal of Computer Assisted Learning, 21(3), 204-216. http://dx.doi.org/10.1111/j.13652729.2005.00128.X

Shen, R., Wang, M., \& Pan, X. (2008). Increasing interactivity in blended classrooms through a cuttingedge mobile learning system. British Journal of Educational Technology, 39(6), 1073-1086. http://dx.doi.org/10.1111/j.1467-8535.2007.00778.x

Shroff, R. H., Deneen, C. D., \& Ng, E. M. W. (2011). Analysis of the technology acceptance model in examining students' behavioural intention to use an e-portfolio system. Australasian Journal of Educational Technology, 27(4), 600-618. Retrieved from http://ajet.org.au/index.php/AJET/article/view/940/216

Smith, S., \& Byrum, D. (2013). Using a BYOD model to teach a graduate level video production course to in-service teachers. In R. McBride \& M. Searson (Eds.), Society for Information Technology \& Teacher Education International Conference. New Orleans, LA: Association for the Advancement of Computing in Education. Retrieved from https://www.learntechlib.org/p/48358

Stavert, B. (2013). Bring your own device (BYOD) in schools 2013 literature review. Eversleigh, NSW: Education \& Communities. Retrieved from https://www.det.nsw.edu.au/policies/technology/computers/mobiledevice/BYOD_2013_Literature_Review.pdf

Sung, Y.-T., Chang, K.-E., Lee, Y.-H., \& Yu, W.-C. (2008). Effects of a mobile electronic guidebook on visitors' attention and visiting behaviours. Educational Technology \& Society, 11(2), 67-80. Retrieved from http://www.ifets.info/journals/11_2/7.pdf

Taneja, A., Fiore, V., \& Fischer, B. (2015). Cyber-slacking in the classroom: Potential for digital distraction in the new age. Computers \& Education, 82, 141-151. http://dx.doi.org/10.1016/j.compedu.2014.11.009

Taylor, S., \& Todd, P. (1995). Assessing IT usage: The role of prior experience. MIS Quarterly, 19(4), 561-570. http://dx.doi.org/10.2307/249633

Toh, Y., So, H. J., Seow, P., Chen, W., \& Looi, C. K. (2013). Seamless learning in the mobile age: A theoretical and methodological discussion on using cooperative inquiry to study digital kids on-themove. Learning, Media and Technology, 38(3), 301-318. http://dx.doi.org/10.1080/17439884.2012.666250

Venkatesh, V., \& Davis, F. D. (2000). A theoretical extension of the technology acceptance model: Four longitudinal field studies. Management Science, 46(2), 186-204. http://dx.doi.org/10.1287/mnsc.46.2.186.11926 
Venkatesh, V., Morris, M. G., Davis, G. B., \& Davis, F. D. (2003). User acceptance of information technology: Toward a unified view. MIS Quarterly, 27(3), 425-478. Retrieved from http://www.jstor.org/stable/30036540

White, D. L. (2015). Gatekeepers to millennial careers: Teachers who adopt technology in education. In Y. Zhang (Ed.), Handbook of mobile teaching and learning (pp. 1-10). Berlin: Springer-Verlag. http://dx.doi.org/10.1007/978-3-642-41981-2_78-1

Corresponding author: Gary Cheng, chengks@ied.edu.hk

Australasian Journal of Educational Technology (c) 2016.

Please cite as: Cheng, G., Guan, Y., \& Chau, J. (2016). An empirical study towards understanding user acceptance of bring your own device (BYOD) in higher education. Australasian Journal of Educational Technology, 32(4), 1-17. 